\title{
Crônica de uma praga anunciada epidemias agrícolas e história ambiental do café nas Américas*
}

\section{Chronicle of a plague foretold crop epidemics and the Environmental History of Coffee in the Americas**}

RESUMO As epidemias agrícolas fornecem um ponto de vista privilegiado para a história ambiental global e transnacional de commodities. A epidemia da ferrugem, causada pelo fungo Hemileia nastatrix, é uma das mais sérias doenças que têm atingido a indústria global de café. No século XIX, ela devastou as plantações de café no Velho Mundo. Também reduziu agudamente a produção de café do tipo arábica na África, Ásia e no Pacífico. Esse foi um dos fatores que permitiu aos países da Américas dominarem a produção global no século XX. Essa epidemia foi detectada nas Américas pela primeira vez na década de 1970. A sua história nas Américas, e as tentativas de seu controle lançam luzes sobre dois paradigmas maiores que moldaram a história ambiental do café no final do século XX. São eles: o paradigma tecnicista, dominante entre meados do século XX até o início

* Artigo recebido em: 18/02/2008, autor convidado.

** Tradução de Regina Horta Duarte 
dos anos 1990; e o paradigma da sustentabilidade, cujo domínio emergiu em meados dos anos 1980 e se mantém até o presente.

Palavras-chave café, epidemia, meio ambiente

ABSTRACT Crop epidemics provide a portal into the global and transnational environmental history of commodities. The coffee rust epidemic, caused by the fungus Hemileia vastatrix, is one of the most serious diseases to have afflicted the global coffee industry. In the nineteenth century, it devastated the coffee plantations in the Old World. It sharply curtailed arabica coffee production in Africa, Asia, and the Pacific. This was one of the factors that allowed the Americas do dominate global coffee production in the twentieth century. The coffee rust epidemic was first detected in the Americas in the 1970s. The history of the rustepidemic in the Americas, and attempts to control it, shed light on two major paradigms that shaped the environmental history of coffee in the late twentieth century. The paradigm of technification, which dominated from the mid-20th century to the early 1990s; and the paradigm of sustainability, which dominated emerged in the mid-1980s and continues to the present.

Key words coffee, epidemics, environment

Os historiadores escreveram extensivamente sobre o café. Em particular, recentes trabalhos sobre as cadeias desta commodity geraram novos vislumbres na história da sua produção, comércio e consumo. Essas análises também ajudaram os historiadores a transcender as limitações de perspectivas limitadas pelo conceito de nação-estado. ${ }^{1}$ Entretanto, mesmo esse novo enfoque tem comparativamente pouco a dizer sobre a história ambiental do café. Alguns trabalhos históricos clássicos incluíram cuidadosas análises ambientais. Vassouras, de Stanley Stein, inclui interessante discussão de como a indústria do café levou à exaustão dos solos. With Broadax and Firebrand, de Warren Dean, explora, em parte, o papel do café na destruição da Floresta Atlântica brasileira. ${ }^{2}$ Alguns estudos recentes na

1 Para uma revisão recente das abordagens da história do café, ver CLARENCE-SMITH, William Gervase \& TOPIK, Steven. The global coffee economy in Africa, Asia, and Latin America. Cambridge: Cambridge University Press, 2005.

2 DEAN, Warren. With broadax and firebrand: the destruction of the Brazilian Atlantic Forest. Berkeley: University of California Press, 1995, chapter 8; STEIN, Stanley. Vassouras: a Brazilian coffee county, 1850-1900. Princeton: Princeton University Press, 1985.

NT: os dois livros citados foram publicados no Brasil (DEAN, W. A ferro e fogo. São Paulo: Companhia das Letras, 1996; STEIN, S. Grandeza e decadência do café no vale do Paraíba: com referencia especial ao município de Vassouras. São Paulo: Brasiliense, 1961.) 
história das ciências agrícolas, como o estudo de André Felipe Cândido da Silva sobre a campanha contra a broca do café em São Paulo, também oferecem nova compreensão da história ambiental do café. ${ }^{3}$ Da mesma forma, grupos de pesquisadores envolvidos nos projetos sobre a História Social da Tecnologia do Café da Universidade Nacional de Costa Rica iniciaram a reconstrução da história social das mudanças tecnológicas (e, por extensão, das mudanças ambientais) em Costa Rica, assim como no âmbito mais amplo da América Central. ${ }^{4}$ Entretanto, a maioria desses estudos possui enfoque local ou nacional. Existem poucas histórias ambientais comparativas ou transacionais do café.

Uma maneira de escrever uma história ambiental transnacional do café é seguir as epidemias que o afetam. As epidemias agrícolas podem ser acidentais, mas elas não são aleatórias. São naturais e antrópicas. Os patógenos causadores de epidemias freqüentemente seguem o movimento de pessoas; a expansão global das epidemias muitas vezes espelha a expansão global de pessoas. Epidemias agrícolas aparecem em paisagens agrícolas, cuja estrutura é formada parcialmente por valores e desejos humanos. São, portanto, eventos fundamentalmente históricos, situados em locais e tempos particulares, modelados simultaneamente por forças naturais e humanas. Tal como as epidemias humanas, as epidemias agrícolas constituem-se em dispositivos úteis que permitem aos historiadores a condução de comparações seriais cruzadas no interior de uma sociedade, assim como comparações históricas de longa duração através de sociedades. As mudanças nos padrões e distribuição de uma epidemia necessariamente se refletem - e causam - mudanças nas relações entre as sociedades humanas e seus ambientes naturais. A história das epidemias agrícolas, portanto, pode oferecer aos historiadores uma importante ferramenta para a escrita da história ambiental das commodities e da agricultura. ${ }^{5}$

A história da epidemia da ferrugem (Hemileia vastatrix) oferece um ponto de vista privilegiado para a história ambiental do café nas Américas, assim como permite situá-las num contexto ecológico global. As Américas dominaram a produção global de café durante 0 século $X X$, pois o acesso à mão de obra, capital e florestas virgens era maior do que o disponível para plantadores de café de outras áreas. Esse domínio também se explica pela devastação - pela ferrugem - das fazendas de café do tipo arábica

3 SILVA, André Felipe Cândido. A campanha contra a broca-do-café em São Paulo (1924-1927). História, Ciências, Saúde - Manguinhos, v.13, n.4, p.947-993, out-dez. 2006.

4 Ver: KUTSCHBACH, Mario Samper, NARANJ O, Carlos, \& SVEZ, Paul. (eds.) Entre la tradic ión y el cambio: evolución tecnológica de la caficultura costarricense. San J osé, C.R.: Universidad Nacional de Costa Rica, 2000.

5 Para outras histórias ambientais e sociais, bastante úteis para o enfoque de epidemias agrárias, ver: SOLURI, J ohn. Banana cultures: agriculture, consumption, and environmental change in Honduras and the United States. Austin: University of Texas Press, 2005; DANQUAH, Francis K. Cocoa diseases and politics in Ghana, 1910-1966. Peter Lang, 1996; MCCANN, J ames. Maize and grace: Africa's encounter with a New World Crop, 1500-2000. Cambridge MA: Harvard University Press, 2005, chapter 6. 
na África, Ásia e Pacífico, durante o final do século XIX. A história dessa epidemia lança luzes sobre uma transformação ambiental fundamental na indústria latino-americana do café, durante meados do século XX. Governos nacionais e organizações multilaterais inauguraram campanhas sistemáticas para transformar e modernizar esse cultivo na América Latina. Essas campanhas foram dirigidas por ideologias de desenvolvimento do pós-guerra, e também pelos temores de revolução camponesa no contexto da Guerra Fria. A ferrugem, que chegou ao Brasil em 1970 e espalhou-se pelo resto do continente na década seguinte, ameaçou o modelo da prosperidade baseada no café. A larga adoção do café tecnicista - parcialmente em resposta à ferrugem - reflete uma das maiores transformações ecológicas nas fazendas latino-americanas, desde os desmatamentos iniciais do século XIX e início do XX. Ao mesmo tempo, essa epidemia explicita os limites dessas organizações nacionais e internacionais em produzir mudanças ambientais. Elas foram incapazes de erradicar ou conter a ferrugem nas Américas, e a tecnicista mostrou não ser a panacéia que esperavam. Desde o fim da Guerra Fria e o colapso do Acordo Internacional do Café, em 1989, os Estados reduziram agudamente seu envolvimento no cultivo de café, ou o eliminaram completamente. A sustentabilidade emergiu como 0 paradigma ecológico e econômico dominante, modelando a indústria do café nas Américas. 0 futuro da ferrugem sob esse paradigma emergente permanece em aberto.

\section{A ferrugem do café e a especialização da indústria global do café, 1870-1950}

A ferrugem do café é, por vezes, conhecida como "malária do café". Tal como a malária, debilita severamente seu hospedeiro, mas raramente o destrói completamente. É causada por um fungo, Hemileia vastatrix, provavelmente originário de algum lugar no sudoeste da Etiópia, onde co-evoluiu com a planta hospedeira. O fungo é um parasita próprio do gênero Coffea: em outras palavras, ataca somente plantas desse gênero. 0 gênero Coffea inclui, grosso modo, setenta espécies, espalhadas através da África equatorial e Madagascar - embora somente um punhado delas tenha algum valor comercial. O fungo inicia seu ciclo vital como um esporo. O esporo, ao cair na superfície inferior de uma folha de café em condições ecológicas adequadas, germina e invade o tecido da folha. 0 fungo cresce e se espalha pelas folhagens, produzindo pontos alaranjados, visíveis a olho nu. Uma única folha infectada pode ter centenas desses pontos. Cada um deles pode liberar centenas de milhares de novos esporos que, por sua vez, podem espalhar-se e infectar outros cafeeiros. O Hemileia vastatrix pode manter-se através de vários ciclos geracionais numa única estação de crescimento (em termos biológicos, é policíclico), de modo a espalhar-se 
rapidamente em condições adequadas; os cafeeiros podem também ser simultaneamente infectados por várias gerações de fungos. Uma infecção grave de ferrugem desfolha o cafeeiro, desprovendo-o de sua capacidade de realizar fotossíntese e desenvolver novos tecidos, incluindo ramos e frutos. Infecções repetidas enfraquecem os cafeeiros e podem causar um agudo declínio na produção. ${ }^{6}$

No ambiente silvestre, a ferrugem é um problema menor. Os cafeeiros são amplamente dispersos através da floresta, diminuindo a densidade de plantas potencialmente hospedeiras. 0 fungo pode se espalhar muito mais rapidamente entre os cafeeiros cultivados, onde as plantas hospedeiras tendem a ser cultivadas em alta densidade. Numa fazenda de café, há poucos obstáculos ou limites para a reprodução e alastramento desse fungo - na verdade, de qualquer outra doença ou peste que se alimente de café. Entretanto, antes dos anos 1860, o café cultivado no mundo permaneceu livre da ferrugem. A indústria mundial do café era baseada em cultivares trazidas do lêmen, mais que da Etiópia. 0 lêmen possuía um ambiente extremamente seco, onde o fungo da ferrugem não podia sobreviver. Em algum momento da década de 1860, o fungo foi acidentalmente carregado do leste da África para o Ceilão, cuja indústria do café tinha se expandido nas décadas anteriores. As densas monoculturas de café do C eilão e suas temperaturas excessivamente secas tornaram-no um local especialmente propício à epidemia. Em 1869, ano em que a ferrugem foi detectada pela primeira vez na ilha, o Ceilão era o terceiro maior exportador mundial de café. Quinze anos depois, a indústria cafeicultora do Ceilão tinha praticamente entrado em colapso. Nas várias décadas seguintes, a epidemia espalhou-se através dos Oceanos Índico e Pacífico. 0 fungo dispersou-se tanto por motivos naturais quanto antrópicos; foi carregado pelas monções, e seguiu a diáspora dos plantadores de café e trabalhadores que deixaram o Ceilão para estabelecer fazendas de café em outros lugares. Destruiu a indústria do café nas Filipinas e suas ilhas menores. Por toda a parte, como em Madagascar e J ava, expulsou o café arábica das planícies e úmidas, onde a epidemia era particularmente grave. Se a doença fosse deixada sem freios, a ferrugem poderia causar perdas entre 20 a $30 \%$ da colheita por ano. ${ }^{7}$

Os cientistas aprenderam muito sobre a ferrugem, mas não puderam descobrir nenhum modo de conter a epidemia, ou curá-la. 0 ciclo de vida

6 Para uma sucinta revisão da ferrugem, ver WINTGENS, J ean Nicolas. (ed.) Coffee Leaf Rust. In: Coffee: growing, processing, sustainable production: a guidebook for growers, processors, traders, and researches. Weinheim: Wiley-VCH, 2004, p.509-518.

7 McCOOK, Stuart. Global Rust Belt: Hemileia vastatrix and the ecological integration of world coffee production since 1850. J oumal of G lobal History, v.1, p.177-195, 2006; WEBB J r., J ames L.A. Tropical pioneers: human agency and ecological change in the highlands of Sri Lanka, 1800-1900. Athens: Ohio University Press, 2002, especially chapters 4 and 5; BARRON, T. J. Science and the Nineteenth-Century Ceylon Coffee planters. J ournal of Imperial and Commonwealth History, v.16, n.1, p.5-21,1987. 
do fungo e sua ecologia foram descritos pelo botânico britânico Harry Marshall Ward, baseado em um extenso trabalho de campo no Ceilão durante o início dos anos 1880. No final do século XIX, os plantadores britânicos descobriram que um fungicida conhecido como "mistura Bordeaux" podia prevenir a contaminação da folha de café - mas somente se fosse aplicado num momento muito exato do ciclo vital do fungo. De qualquer forma, a compra e aplicação da mistura eram muito caras, e ela raramente foi usada antes dos anos 1930. Cientistas e agricultores também procuraram cafeeiros que mostrassem alguma resistência à doença. Plantadores de café da Índia descobriram alguns cafeeiros do tipo arábica aparentemente resistentes à ferrugem. Foram ali largamente plantados, mas pareciam perder sua resistência após a primeira geração. Agricultores e cientistas começaram também a experimentar novas espécies de café. O Coffea liberica foi descoberto nos anos 1870. Seus indivíduos pareciam ser resistentes à ferrugem e foram amplamente plantados no Ceilão, nos anos 1870, e nas Índias Orientais Holandesas, nos anos 1890. Nesses dois lugares, entretanto, o Libérica "perdeu" sua resistência após vários anos. Na década de 1930, o cientista britânico Wilson Mayne descobriu que sua aparente perda de resistência envolvia mudanças no patógeno da ferrugem, mais do que na planta hospedeira. Diferentes "raças" da ferrugem emergiram, cada uma delas especializada no ataque de variedade particular de café. ${ }^{8}$

Em 1990, entretanto, agricultores holandeses introduziram outras espécies de Coffea canephora, variante "robusta", nas Índias Orientais Holandesas. Esse café, conhecido como café robusta - manteve sua resistência à ferrugem. Também possuía muitas vantagens sobre 0 arábica: produzia mais frutos que, por sua vez, possuíam um teor maior de cafeína; podia ser cultivado em planícies e úmidas. Sua única e maior desvantagem era a de que seus frutos não possuíam um sabor tão bom quando os do arábica. Mesmo sendo vendido por um preço mais baixo do que o café arábica, era ainda lucrativo o bastante para que agricultores na África, Ásia e Pacífico o adotassem em larga escala. Após 1900, o robusta se tornou um importante cultivo para pequenos proprietários em lugares diversos como J ava, Uganda, Madagascar, África O cidental Portuguesa e Francesa. Uma linhagem "melhorada" de café robusta circulou entre plantadores, e por uma emergente cadeia de estações experimentais de agricultura colonial. ${ }^{9}$

8 Ver LARGE, E. C. The Advance of the fungi. London: J onathan Cape, 1940, p.196-207; McCOOK, Stuart. Global Rust Belt, p.181-187.

9 CRAMER, P.J.S. A review of literature of coffee research in Indonesia. edited by Frederick L. Wellman. Turrialba, Costa Rica: Inter-American Institute of Agricultural Sciences, 1957. A epidemia da ferrugem contribuiu decisivamente para o rápido declínio da contribuição do Velho Mundo para a produção mundial de café, durante o fim do século XIX e início do XX. CLARENCE-SMITH. The coffee crisis in Asia, Africa, and the Pacific, 1870-1914. In: CLARENCE-SMITH \& TOPIK. The global coffee economy, p.100-119. 


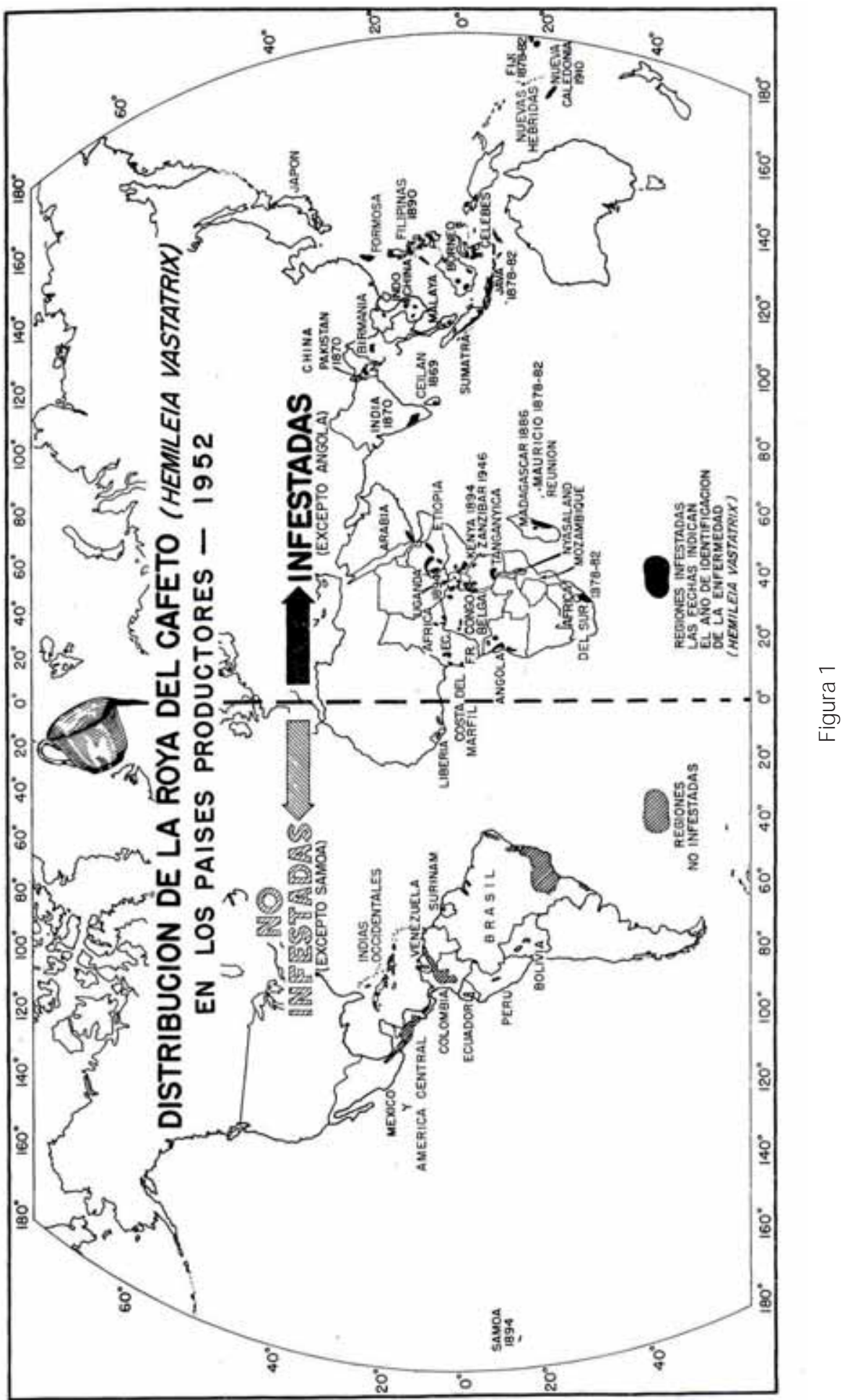


A ferrugem do café ajud ou os produtores americanos a obter um virtual monopólio na produção global de café arábica. Nos anos 1830, o hemisfério leste produziu cerca de um terço do café mundial; por volta de 1905, produziu apenas $5 \%$. Em parte esse dado refletia um declínio relativo entre os dois hemisférios. Nas últimas décadas do século XIX, a produção de café nas Américas (especialmente no Brasil) cresceu mais rapidamente do que em qualquer outro lugar. Parcialmente, isso também refletiu um declínio absoluto na produção, já que muitos plantadores de café no Velho Mundo abandonaram a produção de café arábica. No início do século XX, a maior parte da produção desse café no Velho Mundo estava concentrada em poucos enclaves nas áreas montanhosas no leste da África, Índia e Indonésia, onde as condições ecológicas mantinham a ferrugem em níveis suficientemente baixos para permitir a viabilidade econômica do seu cultivo. Após 1905, o Velho mundo começou a recuperar sua parcela da produção mundial de café - mas a maior parte dela era de café robusta. Por volta de 1950, a ferrugem tinha produzido uma especialização botânica na indústria mundial de café. África, Ásia e Pacifico - onde a ferrugem era presente produziam "robusta" de baixa qualidade e baixo valor. As Américas - até aquele momento ainda livres da ferrugem - produziam valioso (e algumas vezes de alta qualidade) "arábica".

\section{O desenvolvimento global da ciência prepara-se para a ferrugem nas Américas}

Após a Segunda Guerra Mundial, cientistas - e instituições científicas - iniciaram pesquisas sistemáticas sobre o café. Esse fato marca uma aguda ruptura em relação ao período pré-guerra, quando a maioria das potências européias - e, de forma semelhante, as nações independentes da América Latina - dedicavam pouco tempo ao estudo ou ao melhoramento do café. No período pós-guerra, o paradigma do "desenvolvimento" dominou o discurso econômico e global. 0 evangelho do desenvolvimento era promovido por novas e poderosas organizações multilaterais como 0 Banco Mundial, a Organização Mundial de Saúde (OMS) e a Organização para Agricultura e Alimentação (FAO). O desenvolvimento era também propugnado por instituições regionais, como a Organização Pan-Americana de Saúde e o Instituto Interamericano para Ciências Agrícolas. A maior parte das principais potências mundiais também estabeleceu uma ou mais instituições dedicadas a promover o desenvolvimento internacional. Os Estados Unidos, por exemplo, organizou a Agência Para o Desenvolvimento Internacional (USAID). As potências européias reinventaram algumas de suas agências de pesquisa coloniais. Por exemplo, o Escritório de Pesquisa Científica Colonial da França tornou-se o Escritório para Pesquisa Científica e Tecnológica de Além Mar (ORSTOM). As potências ocidentais voltaram-se 
para o estímulo ao desenvolvimento durante as décadas da Guerra Fria. Através do combate à fome e à doença, assim como da promoção do desenvolvimento econômico, esperavam prevenir revoluções comunistas no mundo em desenvolvimento. ${ }^{10} \mathrm{~A}$ agricultura cafeeira surgiu como um veículo ideal para promover desenvolvimento econômico (e estabilidade política) nos trópicos. Poucas economias de escala dedicavam-se à agricultura cafeeira. Essa última, portanto, poderia ser lucrativamente cultivada tanto por pequenos camponeses, como em grandes propriedades. Agências de desenvolvimento e governos começaram a financiar pesquisas nacionais e internacionais sobre o café, com o objetivo de expandir e racionalizar a sua produção.

A instável economia global do café também contribuiu para a pesquisa científica sobre esse tema. Através dos anos 1920 e 1930, houve problemas crônicos de superprodução. Em 1940, os Estados Unidos intermediaram o Acordo Interamericano do Café (AIC) - estabelecendo cotas para cada país produtor latino-americano, como forma de estabilizar o mercado. Após a guerra, o acordo faliu, e os preços do café aumentaram ao longo de quase toda a década de 1950, estimulando nova superprodução global e outra crise do café. Após vários anos de negociação, um novo acordo global foi assinado, incluindo produtores de café na América Latina, África e Ásia. 0 Acordo Internacional do Café foi assinado em 1962, e perdurou até 1989. Visando manter os preços do café em níveis determinados, o acordo estabeleceu cotas de produção. Como resultado, os preços permaneceram relativamente estáveis e altos através dos anos 1960 e 1970. Encorajados pelos altos preços, os produtores de café na América Central, dentre outros, expandiram sua produção de café a despeito das cotas. Por vezes, os países da América Central solicitaram e receberam isenções das cotas do acordo. Venderam o resto de sua produção excedente (a preços mais baixos) para países consumidores não integrados ao AIC. Algumas nações também criaram instituições públicas - como o Instituto Mexicano de Café - que gerenciava a produção doméstica de café e o seu comércio. Muitas dessas organizações nacionais também financiaram pesquisas sobre 0 café. ${ }^{11}$

O crescimento da produção global de café no pós-guerra despertou novamente a epidemia global de ferrugem. $E$ isso ocorreu pelo menos de três maneiras. Em primeiro lugar, novas frentes pioneiras de café foram abertas - especialmente no oeste da África e nas Américas - criando novas paisagens nas quais o fungo poderia se espalhar. Em segundo lugar,

10 STAPLES, Amy L.S. The birth of development: how the World Bank, Food and Agriculture Organization, and World Health Organization changed the world, 1945-1965. Kent, OH: The Kent State University Press, 2006.

11 BATES, Robert H. Open-economy politics: the political economy of the world coffee trade. Princeton: Princeton University Press, 1997, p.136-158; DAVIRON, Benoit \& PONTE, Stefano. The coffee paradox: global markets, commodity trade, and the elusive promise of development. London: Zed Books, 2006, p.83-88. 
as novas práticas agrícolas promovidas por instituições científicas - como plantações densas e a redução da sombra nas fazendas cafeicultoras - aumentaram a produtividade, mas também removeram muitos obstáculos à expansão das doenças e pestes. Em terceiro lugar, o movimento (regulado e não regulado) dos cultivares selecionados do cafeeiro aumentou o risco de que alguma peste ou patógeno indesejado pudesse ser transferido juntamente com a planta.

A epidemia tinha sido efetivamente protelada desde a década de 1930. Nos anos 1950 e 1960 avançou através do oeste da África. Os dois maiores produtores de café da região - Costa do Marfim e Angola - foram fulminados em 1954 e 1966, respectivamente. Como a maioria do café cultivado na região era $C$. canephora, mais que o arábica, a ferrugem não afetou a produção total de café. Entretanto, a epidemia se tornou muito próxima das Américas. Ao longo dos anos 1960, entretanto, as fazendas de café das Américas permaneceriam livres da ferrugem.

Muitos plantadores americanos pareciam indiferentes à possibilidade da travessia do oceano pela ferrugem. Alguns plantadores brasileiros argumentavam que as condições ecológicas das plantações de café no Brasil a impediriam de espalhar-se. Outros diziam que as variedades de café nas Américas seriam resistentes a essa peste. Nos anos 1950 e 1960, à medida que a epidemia se espalhava através do oeste africano, alguns cientistas começaram a expressar a preocupação sobre o risco em que se encontravam as fazendas de café nas Américas. Um deles era Frederick Wellman, fitopatologista destacado para atuar no Instituto Interamericano de Ciências Agrícolas (IICVA), na Costa Rica. A Federação Latino Americana de Produtores de Café (FEDECAME) concordou em financiar uma viagem de Wellman à África e Ásia para estudar a epidemia da ferrugem. Seu relatório final concluiu que o hemisfério ocidental escapara da doença "mais por sorte do que por qualquer outro fator". Wellman recomendou que os pesquisadores nas Américas começassem a cultivar ou selecionar cafeeiros resistentes à ferrugem, ou explorar outras formas de controle da doença. ${ }^{12}$

Em resposta a esse relatório, em 1955, governos de Portugal e das Américas estabeleceram um Centro de Pesquisa sobre o Café (CIFC), em Oeiras, Portugal, financiado conjuntamente pelo Escritório Norte Americano de Relações Agrícolas Estrangeiras e pelo Ministério Português de Relações Além Mar. No momento em que o CIFC foi estabelecido, a ferrugem ainda não tinha alcançado Angola. O CIFC começou a trabalhar no estudo de raças recém descobertas de ferrugem, catalogando 30 delas, cada qual responsável pelo ataque a diferentes variedades de café com intensidades diversas. O CIFC também promoveu pesquisas no cultivo de variedades

12 WELLMAN, Frederick. Hemileia vastatrix. San Salvador: FEDECAME, 1957. 
de café resistentes à ferrugem, em colaboração com outras instituições americanas, como o Instituto Agronômico de Campinas, no Brasil. Talvez a história de maior sucesso do CIFC seja a do café Hibrido de Timor (HdT). Sua expansão a partir de uma minúscula ilha do Pacífico é um produto das interações entre as redes de pesquisa coloniais, nacionais e multilaterais. $\mathrm{O}$ café HdT era um híbrido espontâneo do C. arabica e C. canephora, descoberto na colônia portuguesa do Timor Leste nos anos 1920. No final da década de 1950, foi levado para o CIFC em Portugal, onde os cientistas iniciaram programas de seleção e melhoramento. A partir do CIFC, descendentes melhorados do HdT foram enviados para alimentar programas de pesquisa no Brasil, Colômbia e Costa Rica - onde eram cruzados com cafés arábica locais, na esperança de produzir um café resistente à ferrugem e viável comercialmente. ${ }^{13}$ Tais programas de reprodução, entretanto, ainda estavam em andamento nos anos 1960. Enquanto isso, plantadores de café em várias partes da América Latina estavam adotando novas e mais produtivas variedades do arábica, como o café Caturra. Porém, esse tipo não apresentava resistência especial à ferrugem.

Para a maioria dos produtores de café na América Latina, o risco da ferrugem parecia remoto, e o custo potencial da permuta de variedades permanecia muito alto. Wellman e outros cientistas continuavam preocupados. "Com o estabelecimento da ferrugem nas novas áreas do oeste da África", escreveu Weelman em 1961, "há um perigo crescente de que ela se espalhe pelas Américas. Pela primeira vez, as áreas atacadas pela ferrugem estão na direção dos ventos e das tempestades que ligam os países africanos contaminados pela ferrugem às plantações de café nas Américas". ${ }^{14}$

\section{A epidemia de ferrugem do café nas Américas}

Em janeiro de 1970, o pesquisador brasileiro Arnaldo Gomes Medeiros, especializado em cacau, conduzia pesquisas perto da cidade de Ubaitaba, na Bahia, quando notou que as folhas de um cafeeiro estavam infectadas pela ferrugem. As folhas foram enviadas para o CIFC em Portugal, onde pesquisadores confirmaram a contaminação. Até hoje não está claro e quando exatamente a ferrugem alcançou o Novo Mundo. Esporos do fungo podem ter sido carregados pelos ventos a partir das novas fronteiras do café em Angola ou Costa do Marfim, onde a ferrugem tinha sido inicialmente detectada há apenas alguns anos. Mesmo que correntes de vento disse-

13 AVELINO, J acques; MULLER, Raoul; ESKES, Albertus; SANTACREO, Rodney; \& HOLGUÍn, Francisco. La roya anaranjada del cafeto: mito y realidad. In: BERTRAND, Benoît \& RAPIDEL, Bruno. (eds.) Desafios de la caficultura en Centroamérica. San J osé, C.R.: IICA/PROMECAFE/CIRAD/IRD, 1999, p.227-233; CARVALHO, A. \& MONACO, L.C. Melhoramento do Cafeeiro visando a resistência a ferrugem alaranjada. Ciência e Cultura, São Paulo, v.23, p.141-146, 1971; ESKES, A.B. \& LEROY, T. Coffee selection and breeding. In: Coffee: growing, processing, sustainable production, p.60-61.

14 WELLMAN, Frederick. Coffee: botany, cultivation, and utilization. London: Leonard Hill, 1961, p.255. 
minassem a ferrugem sobre longas distâncias na África, alguns cientistas duvidaram de sua habilidade de viajar através do oceano. A ferrugem pode ter sido introduzida acidentalmente desde o oeste da África, em material agrícola infectado ou algum outro vetor - incluindo humanos. Uma vez que a doença se estabeleceu no Brasil, espalhou-se muito rapidamente..$^{15}$

A explosão da ferrugem na América Latina também se apresentou como um problema potencialmente social e político. Alguns comentaristas temeram que a epidemia pudesse produzir intranqüilidade entre os produtores camponeses, aumentando o espectro de uma revolução. Alguns dos produtores líderes - Colômbia, El Salvador, Guatemala e Nicarágua - já enfrentavam conflitos camponeses internos. Os economistas desenvolveram predições sinistras sobre os potenciais impactos da ferrugem sobre as economias latino americanas. Um economista da América Central alertou para a necessidade "de compreensão da importância de uma perda econômica causada diretamente pela ferrugem na atividade da indústria do café, acarretando uma profunda depressão em atividades do sistema bancário, industrial, comercial e de serviços, conseqüente e indiretamente afetando as classes trabalhadoras". Ele calculou que perdas de $5 \%$ da produção de café nas áreas que incluíam Panamá, América Central e México, levariam ao prejuízo de $\$ 22$ milhões de dólares e de 7.750 .000 dias de trabalho. No cenário mais pessimista de $30 \%$ de perdas, o prejuízo seria de $\$ 132$ milhões de dólares e 46.500 .000 dias de trabalho. Concluía que, " mesmo no caso de $5 \%$ de perda causada pela ferrugem, haveria um impacto realmente negativo no desenvolvimento econômico e social desses países, com grandes distúrbios na sua ordem política interna...". ${ }^{16}$ Tais temores de revolução foram raramente expressos de forma explícita, mas moldaram os programas de desenvolvimento através das Américas.

Governos e instituições de pesquisa através das Américas mobilizaramse quase imediatamente. Em fevereiro de 1970, o governo brasileiro criou a CEFCA (Comissão Executiva da Erradicação da Ferrugem do Cafeeiro) para estudar a doença e buscar sua erradicação. A CEFCA inspecionou a região infestada, e retornou com notícias desencorajadoras. A ferrugem se espalhara desde áreas isoladas sobre uma região de mais de $500.000 \mathrm{~km} 2$, a maior parte situada no estado da Bahia. A doença provavelmente existia no Brasil há vários anos, mas não havia sido detectada devido à existência de pouquíssimos pesquisadores sobre o café naquela parte do país. Em março de 1970, apenas dois meses após a descoberta de Medeiros, 0 CIRSA (Comitê Internacional Regional de Sanidad Agropecuária) convocou

15 WALLER. Coffee rust in Latin America, p.403; MULLER, R. A. La rouille du caféier (Hemileia vastatrix) sur le continent Américain. Café, Cacao, Thé, v.15, n.1, p.24-30, janvier-mars 1971; BOWDEN, J .; GREGORY, P.H.; \& J OHNSON, C.G. Possible wind transport of coffee leaf rust across the Atlantic Ocean. Nature, v.229, p.500-501, 1971.

16 MUYSHONDT, M. Apud SCHIEBER. Economic impact of coffee rust. Annual Review of Phytopathology, v.10, p.505, 1972. 
um encontro para discutir o problema. O CIRSA encarregou o Instituto Interamericano de Ciências Agrícolas (IICA), na Costa Rica, de estudar a ferrugem e de ajudar outros países a gerenciar a epidemia. 0 diretor do IICA alertou para os danos econômicos em potencial que a doença poderia causar, citand o o exemplo do Ceilão e salientando o fato de que o café era o primeiro ou segundo mais importante produto de exportação para treze países da América Latina. Ele conclamou a uma "resposta continental" à epidemia, concentrada em quarentenas, no controle da doença, e na busca por variedades resistentes. Adicionados a esses esforços científicos internacionais, campanhas nacionais contra a ferrugem também buscavam recrutar a ajuda de todos nas zonas cafeeiras. ${ }^{17}$

A ferrugem rapidamente superou os esforços para sua erradicação ou contenção. A doença levara 50 anos para atravessar a África de leste a oeste; mas se espalhou através das Américas em menos de 15 anos. Como nos surtos anteriores, o vento foi o maior fator na expansão dos esporos da ferrugem a nível local e regional. Os esporos seriam levados de uma fazenda infectada para as vizinhanças. No Brasil, a ferrugem se espalhou por mais de $1.000 \mathrm{~km}$ em 18 meses, impulsionada em grande parte, provavelmente, pelos ventos. Alguns plantadores de café esperavam que a epidemia fosse contida pela Cordilheira dos Andes e pela Bacia Amazônica - um pouco como as selvas da África central tinham detido (ou desacelerado) a expansão da ferrugem do leste para o oeste africano. Entretanto, a epidemia também se movia por fatores antrópicos. Os esporos da ferrugem agarravam-se nas roupas e objetos das pessoas de passagem pelas fazendas infectadas, viajavam ao longo das trilhas, estradas, rodovias, e rotas aéreas que crescentemente ligavam o continente. A ferrugem algumas vezes viajou imperceptível em mudas de variedades melhoradas de café difundidas através das Américas. 0 cientista britânico, J ames Waller, escrevendo em 1972, concluiu que "os países latino-americanos precisavam compreender as implicações de, mais cedo ou mais tarde, conviver com a ferrugem do café". ${ }^{18} \mathrm{Em} \mathrm{1975}$, a ferrugem galgou as áreas entre o Brasil e a América Central - a maior parte certamente espalhada mais pelas ações humanas do que pelo vento. A epidemia apareceu na Nicarágua, num pequeno e isolado distrito próximo à cidade de Carazo. Provavelmente foi introduzida acidentalmente por um plantador de café de passagem por alguma região infectada no Brasil. ${ }^{19}$

Com a expansão da doença, a maior parte dos países respondeu de formas similares. Primeiramente, estabeleceram quarentenas em suas

17 MULLER. La rouille du caféier sur le continent Américain, p. 25-27; IICA, Réunión técnica sobre las royas del cafeto. San J osé, CR/IICA, 1970.

18 WALLER. Coffee rust in Latin America, p.407.

19 SCHIEBER, Eugenio Schieber \& ZENTMYER, George. Coffee rust in the Western Hemisphere. Plant Disease v.68, n.2, p.89-90, February 1984. 
fronteiras, visando prevenir a entrada da doença. A maioria dos países também realizou campanhas nos meios de comunicação, mostrando às pessoas como reconhecer a doença e o que fazer se a encontrassem. É o caso do Instituto Brasileiro do Café, que planejou uma intensa campanha, incluindo "TV, jornais radiofônicos, comícios, escolas e igrejas de todas as áreas cafeicultoras do país, sobre a severa ameaça à economia da nação, visando obter a colaboração de todos". Esses programas de controle e campanhas nos meios de comunicação ajudaram, em alguns casos, a diminuir a expansão da ferrugem. Colômbia e Costa Rica, particularmente, evitaram a ferrugem por vários anos, após seus vizinhos mais próximos terem sido infectados. Esse lapso de tempo deu aos produtores de café colombianos e costarriquenhos mais tempo para se prepararem contra a epidemia. ${ }^{20}$

O governo da Nicarágua iniciou uma campanha para erradicar a doença, com ajuda técnica e financeira de outros países produtores da América Central e da Agência Alemã para Cooperação Técnica (GTZ), uma agência internacional de desenvolvimento da Alemanha Ocidental. Inicialmente, a campanha prometia sucesso, com programas agressivos de quarentena e pulverização, com índices de doença virtualmente reduzidos a zero por várias estações. Mas a cada nova estação, aparecia um novo surto. Sprays químicos e quarentenas não foram suficientes para conter ou erradicar completamente a infecção. De acordo com J ames Waller, nem sempre as zonas livres em torno de árvores infectadas recebiam aplicações mais amplas, devido a "considerações políticas e econômicas" - em suma, muitas das fazendas de café nessas áreas eram propriedades de aliados da ditadura de Somoza. Por volta de 1979, esse governo gastou mais de 20 milhões de dólares lutando contra a ferrugem. Os programas somozistas de pulverização foram interrompidos pela revolução Sandinista de 1979. Em 1980, o governo Sandinista começou sua própria luta contra a ferrugem, iniciando um programa agressivo para "renovar" fazendas de café nas áreas infestadas mas, nesse momento, a epidemia tinha se espalhado para além de seus focos iniciais. Logo, focos de infecção começaram a aparecer em plantações de café por toda a parte na Nicarágua e além. ${ }^{21}$

Através do final dos anos 1970 e início dos anos 1980, a ferrugem do café se espalhou além de seus focos no Brasil e Nicarágua. A partir do foco

20 GERCA. A ferrugem do cafeeiro no Brasil. Rio de J aneiro: IBC, 1970; FEDECAFÉ. Actividades de la campaña contra la roya del cafeto. Bogota, 1971.

21 WALLER, J.M. Coffee rust-epidemiology and control. Crop Protection, v.1, n.4, p.388-389, 1982; WALLER, J.M. The recent spread of coffee rust (Hemileia vastatrix) and attempts to control it. In: EBBELS, D.L. \& KING, J .E. (ed.) Plant Health. Oxford: Blackwell Scientific Publications, 1979, p.275-283; GTZ. Lucha contra la roya del café . Eschborn: GTZ, 1979; RICE, Robert A. Transforming agriculture: the case of coffee leaf rust and coffee renovation in southern Nicaragua. Berkeley: University of California, 1990 (PhD Dissertation), p.53-74; SHCHUPPENER, H.; HARR, J .; SEQUEIRA, F.; GONZALES, A. First occurrence of the coffee leaf rust Hemileia vastatrix in Nicaragua, 1976, and its control. Café, Cacao, Thé, v.21, n.3, p.197-20, juillet-septembre 1977. 
brasileiro, avançou sobre algumas zonas do Paraguai e Argentina, em 1972, e então, significativamente, para plantações no Acre, no extremo oeste da Amazônia brasileira, em 1975. A ferrugem pode ter sido carregada do Acre para a Bolívia e infestado mudas. Da Bolívia, a doença aparentemente dirigiu-se ao norte da Cordilheira dos Andes, possivelmente carregada em mudas ou pelo vento. As infecções também se espalhavam ao longo das rodovias regionais, indicando que a doença também viajava sobre rotas de transporte terrestres. Como em outros lugares, as maiores tentativas de quarentena se mostraram inúteis. A ferrugem apareceu no Peru (1979), Equador (1981), e finalmente na Colômbia (1983). Na América Central, a doença não se espalhou da forma como os cientistas haviam predito. A área infestada da Nicarágua foi fechada para as zonas de café da Costa Rica que, por sua vez, permaneceram livres da doença até 1983, possivelmente devido às medidas agressivas de controle da doença. Em lugar disso, a epidemias primeiramente moveram-se em direção ao norte, invadindo EI Salvador - contra a direção predominante do vento. A epidemia se espalhou ao longo de trilhos e da rodovia Pan-Americana. Como na Nicarágua, as regiões de Guerra Civil moldaram a expansão da doença. "Um dos fatores responsáveis pelo recente surto em EI Salvador", escreveram dois cientistas em 1984, "pode ter sido o movimento de pessoas naquela área, intensificado especialmente por fatores políticos. É bem possível que a ferrugem tenha sido trazida por pessoas em trânsito da Nicarágua para El Salvador". A epidemia alcançou EI Salvador em 1989, Honduras e Guatemala, em 1980 e México, em 1981.22

Foi (e permanece) difícil estimar o impacto da epidemia na safra de café nas Américas. A ferrugem era apenas um dos fatores que modelavam a produção cafeicultora durante esses anos altamente voláteis. Talvez 0 maior impacto na produção da época tenha sido a geada de 1975 no sul do Brasil, que dizimou dezenas de milhões de cafeeiros. As baixas temperaturas iriam também matar, temporariamente, os fungos, embora em poucos anos a zona cafeicultora provavelmente tenha sido reinfectada. As constantes ondas de inovações, ao longo dos anos 1970 e 1980, também mostram como cafeicultores reagiam à medida que eram golpeados - e essas inovações amainavam alguns dos impactos causados pela ferrugem. Da mesma forma, o impacto da epidemia era também menos severo em áreas mais quentes ou mais frias do que nas regiões úmidas e baixas. Alguns estudos locais sugerem que a epidemia causava quedas na produção - especialmente onde não eram tomadas medidas de controle. No Brasil,

22 SCHIEBER, Eugenio \& ZENTMYER, George. Coffee rust in the Western Hemisphere. Plant Disease, v.68, n.2, p.89-90, February 1984; SCHIEBER, Eugenio \& ZENTMYER, George. Distribution and spread of coffee rust in Latin America. In: FULTON, R. (ed.) Coffee rust in the Americas. St. Paul: American Phytopathological Society, 1984, p.1-14; WALLER, J.M. Coffee rust - epidemiology and control. Crop Protection, v.1, n.4, p.388-389, 1982. 
estudos mostraram que tais perdas podiam alcançar $30 \%$ da produção; em El Salvador, Honduras, e Guatemala, estudos similares mostraram perdas de 28,40 e $21 \%$ respectivamente. As perdas não eram tão grandes, naturalmente, em fazendas que tomaram algum tipo de medida de controle. Mesmo nesses casos, entretanto, as perdas financeiras potencialmente causadas pela ferrugem podiam ser grandes. Em meados da década de 1980, um cientista calculou que, no Brasil, a ferrugem causou entre um e três bilhões de dólares de perdas anuais. ${ }^{23}$

À medida que a doença se espalhou de um lado a outro das Américas, cultivadores e cientistas procuraram freneticamente por uma medida de controle efetivo. Após um curto período, a principal resposta foi o uso de sprays químicos derivados do cobre - como aqueles usados nas fazendas cafeicultoras da Índia e Kenia. Os sprays - se usados apropriadamente - poderiam reduzir significativamente a intensidade da ferrugem e manter altos os níveis produtivos. Entretanto, a pulverização por fungicidas não era, necessariamente, uma panacéia contra a ferrugem. Medida prática nas paisagens relativamente planas do Brasil, era muito mais difícil de ser realizada nas encostas íngremes ao norte da América Latina. A pulverização também demandava o acesso a abundantes suprimentos de água, para a mistura dos produtos químicos. Representava, ainda, uma despesa adicional para os cafeicultores, requisitando uma força de trabalho cara, tecnologia e produtos químicos. Raoul Muller, fitopatologista e diretor de pesquisa no ORSTOM - agência internacional de desenvolvimento francesa - argumentou que o controle químico era necessário durante um período curto. Entretanto, temia que o uso regular de fungicidas pudesse representar "um fardo permanente" entre os cafeicultores, e que, em pequenas propriedades, "a produtividade (do café) não fosse suficiente para cobrir os custos dessas intervenções". ${ }^{24}$

Governos e agências internacionais de desenvolvimento responderam a esse problema promovendo a "tecnificação" do cultivo de café, tanto no caso de grandes plantadores como de pequenos proprietários. Em teoria, um programa amplamente baseado na tecnicista ajudaria os cafeicultores a aumentar sua produção - algumas vezes até 300\%. Esse aumento contrabalançaria, teoricamente, o custo da "tecnificação" das fazendas e a necessidade de produtos químicos necessários no combate à doença e à manutenção da produção. Mesmo antes do surto da ferrugem, cafeicultores

23 GÁLVEZ, Gloria Cecilia; MONTOYA, Margarita \& OSORIO, Mario Córdova. Estudio epidemiológico de la roya del cafeto (Hemileia vastatrix Berk \& Br.) en EI Salvador. In: V Simposio latinoamericano sobre caficultura. San Salvador/EI Salvador, 20-22 October 1982, p.138; AVELINO, J acques; MULLER, Raoul; ESKES, Albertus; SANTACREO, Rodney \& and HOLGUÍN, Francisco. La roya anaranjada del cafeto: mito y realidad. In: Desafios de la Caficultura en Centroamérica, p.216-218; ESKES, A.B. Resistance. In: KUSHALAPPA A. C. \& ESKES, A. B. (eds.) Coffee rust: epidemiology, resistance, and management. Boca Raton/FL: CRC Press, 1989, p.175; KUSHALAPPA A. C. Biology and Epidemiology. In: Coffee rust: epidemiology, resistance, and management, p.65-68.

24 MULLER, R.A. La rouille du caféier sur le continent Américain, p. 28. 
de toda a América Latina vinham introduzindo inovações por várias décadas. ${ }^{25}$ Entretanto, o programa de "tecnificação" empreendido na década de 1970 era diferente em dois aspectos. Primeiramente, era promovido como um "pacote" de transformações que afetavam todas as facetas do cultivo de café, opondo-se às inovações gradativas dos primeiros tempos. De acordo com um documento publicado pela USAID,

\begin{abstract}
"tecnificação" refere-se a uma combinação de medidas, incluindo poda científica, sombreamento, aplicação de fertilizante, inseticidas e fungicidas, plantio de variedades altamente produtivas logo que elas se tornem disponíveis, e aumento do número de plantas por manzana (unidade de área correspondente a 0.69 hectares ou 1,7 acres). ${ }^{26}$
\end{abstract}

Em segundo lugar, a "tecnificação" conduzida nos anos 1970 - diferentemente dos primeiros esforços - era financiada e promovida sistematicamente por governos nacionais, associações de plantadores de café, e agências internacionais de desenvolvimento. Esses grupos ofereciam suporte financeiro e técnico aos fazendeiros que decidissem "tecnificar" suas propriedades.

No início dos anos 1980, o pacote de "tecnificação" também passou a incluir alguns dos híbridos de café resistentes à ferrugem e comercialmente viáveis. Nos anos 1970, cafeicultores renovaram suas fazendas com cafeeiros "anões" altamente produtivos desenvolvidos no Brasil, como o Caturra e - Catuaí. As variedades eram também conhecidas como "cafeeiros a pleno sol", uma vez que podiam crescer sem sombreamento. Ao desenvolver-se completamente ao sol, com fertilizantes químicos, poderiam produzir até três vezes mais do que os cafeeiros tradicionais. Em muitas fazendas "tecnificadas", o sombreamento foi reduzido ou eliminado. Os cafeeiros Caturra e Catuaí não tinham resistência especial à ferrugem, e exigiam controle químico contínuo. No início dos anos 1980, o CIFC - em cooperação com parceiros de toda a América Latina - produziu vários híbridos que pareciam potencialmente comerciais. A maioria desses híbridos, conhecidos como Catimor, baseavam-se em cruzamentos entre o Híbrido de Timor (HdT) e o Caturra. $\mathrm{O}$ café $\mathrm{C}$ atimor foi originalmente desenvolvido pelo CIFC de Portugal. Cultivadores da América Latina, por sua vez, cruzaram o Catimor com variedades locais do arábica. A Federação Colombiana dos Cafeicultores introduziu a Variedade Colômbia, cruzamento entre HdT e Caturra, em 1982. Ela foi largamente adotada por plantadores colombianos nos anos 1980. Os cafés híbridos tinham as propriedades de resistência à ferrugem do café

25 Ver, por exemplo, SAMPER, Mario; NARANJ O, Carlos \& SFEZ, Paul. (eds). Entre la tradición y el cambio: evolución tecnológica de la caficultura costarricense. San J osé: Universidad Nacional de Costa Rica, 2000.

26 USAID report, 1981, Apud: RICE, RobertA. \& WARD, J ustin R. Coffee, conservation, and commerce in the Western Hemisphere. Smithsonian Migratory Bird Center, White Paper n.2 .Washington/New York: Smithsonian Migratory Bird Center/ NRDC, 1996. 
robusta, ao mesmo tempo em que mantinham o sabor suave dos cafés arábica. Para vários cientistas e funcionários das agências, a "tecnificação" surgiu como chave da promoção do desenvolvimento econômico dos pequenos proprietários cafeicultores, ao mesmo tempo em que controlaria a iminente epidemia da ferrugem. ${ }^{27}$

Os custos da produção nas fazendas "tecnificadas" podiam ser oito vezes maiores do que nas fazendas tradicionais. Os produtos químicos podiam representar até um quarto dos custos da produção. Os gastos com mão de obra especializada em aplicar os agrotóxicos, e também na poda e manutenção das árvores eram muito mais altos do que nas fazendas tradicionais. Mesmo com essas despesas adicionais, o café "tecnificado" podia apresentar um custo efetivo à medida que os preços do café permaneciam suficientemente altos. Em 1975, os preços globais do café oscilaram após uma geada que golpeou as fazendas do sul do Brasil, com um declínio dramático na produção brasileira. Entre julho de 1975 e julho de 1976, os preços do café subiram mais que o dobro, de 38c/lb para $68 \mathrm{c} / \mathrm{lb}$. Em julho de 1978 , os preços dobraram novamente, alcançando quase $140 \mathrm{c} / \mathrm{lb} .{ }^{28} \mathrm{~A}$ geada havia danificado as árvores tão severamente que o Brasil foi incapaz de alcançar a quota produtiva estabelecida pelo Acordo Internacional do Café. Outros países da América Latina expandiram sua produção e suas exportações, suprindo o déficit representado pela queda da produção brasileira e se beneficiando da alta dos preços.

No início da década de 1990, os produtores de café da América Latina tinham "tecnificado" suas fazendas. A bióloga Ivette Perfecto estimou que "quase a metade da área de produção cafeeira ao norte da América Latina foi transformada por volta de 1990", embora esse fato não tenha ocorrido uniformemente. No topo da escala, a Colômbia "tecnificou" $69 \%$ de suas plantações de café; Costa Rica 40\%, Honduras 35\%, Nicarágua 29\% e Guatemala $20 \% \%$. A despeito de programas promotores do avanço técnico, o México "tecnificou" apenas $17 \%$ de sua produção, enquanto El Salvador, revolto pela guerra civil, $8 \% .^{29}$

A "tecnificação" não era uma panacéia para a ferrugem, nem para os problemas financeiros vividos pelos cafeicultores. Nem todos os pequenos proprietários - especialmente no México e na América Central - adotaram a prática. Os dados da Colômbia sugerem que muitos pequenos produtores

27 Ver: RODRIGUES J r., C.J . \& ESKES, A.B. Resistance to coffee leaf rust and coffee berry disease. In: Coffee: growing, processing, and sustainable production, p.551-564.

28 Os dados sobre os preços de produtores foram retirados de Historical Data series. International Coffee Organization. < http://www.ico.org/historical.asp> 12 J uly 2005. Os preços de produtores de Costa Rica foram usados para ilustração; o preço para outros produtores da América Latina podem ter tido variações, mas todos seguiram a mesma tendência.

29 PERFECTO, Ivette; RICE, Robert A.; GREENBERG, Russell; VAN DER VOORT, Martha E. Shade coffee: a disappearing refuge for biodiversity. BioScience, v.46, n.8, p.598-608, Sep.1996; RICE, Robert A. The land use patterns and the history of coffee in eastern Chiapas, Mexico. Agriculture and Human Values, v.14, p.127-143, 1997. 
nessas áreas não o fizeram abertamente, assim como outros na Costa Rica. No México, programas de crédito e assistência técnica pelo INMECAFEs tiveram adesão considerável de pequenos produtores. Contudo, somente $22 \%$ dos pequenos produtores desse país (com propriedades de área igual ou menor que 3 hectares) realmente aderiram ao café "tecnificado". Estudos comprovam que os técnicos do INMECAFE deram tratamento preferencial aos maiores produtores, com "uma correlação positiva entre a grande propriedade e o gerenciamento intensivo ("tecnificação") da fazenda". ${ }^{30}$ Por toda a América Central, cafeicultores eram mobilizados por outras questões durante as décadas de 1970 e 1980. Disputas civis em graus variados varreram a Guatemala, El Salvador e Nicarágua. Pequenos camponeses envolveram-se freqüentemente nos conflitos, ou eram forçados a fugir de suas terras. Igualmente, grandes proprietários buscavam minimizar suas despesas face aos tumultos, ou simplesmente abandonavam suas fazendas. Em Brasil, de acordo com um relato, muitos lavradores, incapazes de bancar o controle da doença, abandonaram suas roças e mudaram-se para o norte para se tornarem garimpeiros. ${ }^{31}$

Esses números mostram que na maior parte dos países, a maioria dos cafeicultores não incrementou tecnicamente suas fazendas ou, pelo menos, não adotou o "pacote" inteiro, tal como encorajado pelas agências. Isso requer alguma explicação. Parcialmente, o problema reside em definir, pois qualquer avaliação depende pesadamente da definição de "tecnificação" utilizada como referência. Muitos fazendeiros continuaram a cultivar o café de formas tradicionais. Seu fracasso em "tecnificar" pode ser parcialmente explicado por preferências burocráticas ou pela ineficiência, mas também pelos altos custos da "tecnificação", ou ainda pelos conflitos civis. Gabriela Cadena, líder do centro Cenicafé de pesquisa na Colômbia, notou que "nem todos os camponeses podem esperar os dezesseis meses necessários para o início da produção (do café variedade Colômbia)".32 Alguns observadores também explicaram esse fato pelo conservadorismo ou ignorância dos camponeses. Retrospectivamente, parece provável que muitos plantadores de café simplesmente decidiram que a "tecnificação" não valia a pena. Muitos camponeses cultivavam, além do café, uma série de produtos para subsistência ou venda, como forma de gerenciar os riscos econômicos e ecológicos. Eles produziam café, mas não eram cafeicultores. Em muitos casos, a ferrugem não alcançou um impacto tão severo entre nesses pequenos produtores tal como alcançou entre os maiores. 0 alto grau de diversidade biológica nas fazendas camponesas tradicionais inibiu a

30 NESTEL, David. Coffee in Mexico: international market, agricultural landscape, and ecology. Ecological Economics, v.15, p.165-178, 1995; RICE. Coffee in eastern Chiapas, p. 127-143.

31 KUSHALAPPA. Rust management, p.133; KUTSCHBACH, Samper. Trayectoria y viabilidad de las caficulturas centroamericanas, p.47-55.

32 El viejo Caldas. Semana, Bogotá, 30/07/1990. 
expansão da ferrugem e limitou seu impacto. Outros fazendeiros, orientados mais comercialmente, resistiram à "tecnificação", pois estavam preocupados de que as novas variedades e híbridos gerassem produtos de qualidade inferior. A Associação de Cafeicultores da Guatemala (ANACAFE) acreditou que - para o café cultivado em altitudes maiores de 1200m (4000 pés) - o Bourbon, variedade tradicional do arábica, produziria frutos de melhor qualidade do que o híbrido Catimor. A diferença no sabor era significante, já que os cafés de alta qualidade freqüentemente atraíam melhores preços nos mercados internacionais. 33

Em meados dos anos 1980, a ferrugem tinha se espalhado por quase todos os cantos das Américas. Não causava mais o pânico que despertara na década anterior, quando os surtos de ferrugem fizeram as manchetes dos jornais nacionais através do continente. Mas a ferrugem tornara-se endêmica, exigindo a constante atenção dos cientistas e planejadores. A ferrugem passou a ser algo como um anticlímax, em grande parte do hemisfério oeste. Seu impacto foi, em parte, limitado pelos esforços dos cientistas. As pulverizações químicas ajudaram a limitar o impacto dos surtos. A introdução de híbridos resistentes, como o Caturra, limitou o impacto entre produtores altamente "tecnificados", como na Colômbia e na Costa Rica. Fatores ecológicos também ajudaram. Muitas plantações de café situavam-se em locais de altas altitudes, o que fazia com que elas fossem expostas, periodicamente, a baixas temperaturas, inibindo o desenvolvimento da epidemia. Da mesma forma, muitas regiões cafeicultoras enfrentavam uma longa e específica estação seca, o que limitava a proliferação dos esporos, tornando o controle relativamente fácil. As condições de produção do pequeno cafeicultor podem ter limitado a expansão. Em áreas de produção mista, outros plantios podem bloquear a difusão da ferrugem. As condições dessas fazendas eram estruturalmente similares às florestas da Etiópia, onde o café cresce livremente, e onde a ferrugem é endêmica, mas em níveis muito baixos.

\section{Da "tecnificação" à sustentabilidade: a ferrugem e a crise do café a partir de 1989}

Em 1989, os produtores mundiais de café começaram a sofrer uma série de choques. Os paradigmas do desenvolvimento, que tinham governado a indústria global do café desde o início dos anos 1960, se desmantelaram. O fim da Guerra Fria transformou o contexto geopolítico da produção de café. Os Estados Unidos e seus aliados ocidentais não experimentavam mais a iminência de uma crise, o que tinha moldado, até então, grande

33 ANACAFE. Manual de caficultura. 3.ed. Guatemala: ANACAFE, 1998, p.33. 
parte de suas políticas de desenvolvimento em direção à América Latina. Com o colapso do Bloco Soviético em 1989, os Estados Unidos perderam sua motivação principal para participar no Acordo Internacional do Café. 0 acordo e o sistema de quotas extinguiram-se em 1989. Produtores de café de todo o mundo começaram a aumentaram suas exportações, e os preços internacionais começaram a cair. Os preços do café colombiano caíram de 149c/lb, em março de 1989, para 59c/lb, em abril de 1993. Houve uma breve recuperação em meados dos anos 1990, após uma geada no Brasil, com nova queda vertiginosa no início do século XXI. ${ }^{34}$ Somado a isso, o Vietnam expandiu significativamente sua produção de café nos anos 1990, inundando o mercado com cafés baratos (tipo robusta), contribuindo para a depressão global dos preços de café. Em muitos casos, os preços recebidos pelos produtores caíram abaixo dos custos da produção.

Os cafeicultores latino-americanos também enfrentaram uma crise institucional. Como parte dos programas estruturais de regulação (SAPs), impostos por agências multilaterais de empréstimo, governos latino-americanos cortaram verbas destinadas a agências públicas. Associações nacionais de café e centros de pesquisa agrícola tiveram seus orçamentos drasticamente reduzidos. Duas das organizações nacionais de café líderes da América Latina - a INMECAFE, do México, e o Instituto Brasileiro de Café - fecharam, simultaneamente. A Federação Nacional de Cafeicultores Colombianos, fundada por uma taxa das exportações de café, foi forçada a cortar despesas. Em suma, cultivadores das Américas perderam a maior parte do suporte econômico recebido nas décadas anteriores.

Esses choques mesclaram crises econômicas e ecológicas em fazendas de café latino-americanas. Ironicamente, as crises eram freqüentemente mais severas nas fazendas mais "tecnificadas". Mesmo aquelas organizações que tinham mais incisivamente advogado a "tecnificação" começaram a questioná-la. Um artigo de debate de co-autoria entre o Banco Inter-Americ ano de Desenvolvimento (USAID) e o Banco Mundial questionou o valor da "tecnificação":

Nos casos onde a adoção de novas variedades e agrotóxicos foram introduzidos como um "pacote" sem a devida observância da sustentabilidade ambiental, o aumento da produção foi alcançado. Lamentavelmente, entretanto, a decisão de "tecnificar" a produção foi muitas vezes uma proposição fracassada. Novas variedades e o uso crescente de agrotóxicos não resultaram em safras maiores. A implementação de novas tecnologias alterou o ecossistema natural, forçando os produtores a aumentar continuamente a quantidade de agrotóxicos usados.

34 Dados da International Coffee Organization's Historical Data series, disponível online em <ttp://www.ico.org/historical.asp > acesso em 12 de julho de 2005. Pendegrast, Uncommon Grounds, ch.16. Ver também: DICUM, Gregory; LUTTINGER, Nina. The coffee book: anatomy of an industry from crop to the last drop. New York: New Press, 1999. 
Essas práticas não apenas danificaram o meio ambiente, mas sobretudo minaram a competitividade da indústria de café. ${ }^{35}$

A situação era particularmente grave para os produtores colombianos. Nos anos 1980, esses cafeicutores haviam se endividado pesadamente para converter suas fazendas à "Variedade Colombia", resistente à ferrugem. Eles esperavam que o aumento da produção os ajudaria a saldar suas dívidas. Mas assim que as árvores alcançaram a maturidade, os preços do café despencaram e a produção não foi suficiente para cobrir seus empréstimos. ${ }^{36}$

A crise do café pode ter contribuído para o surgimento de vários surtos graves de ferrugem, durante os anos 1990. A doença é atualmente endêmica através das Américas mas, durante a década de 1980, os cafeicultores desenvolveram formas de gerenciá-la. Entretanto, a crise impôs novos limites nas formas como os cafeicultores poderiam responder à epidemia. $\mathrm{Na}$ verdade, foram localizadas graves surtos de ferrugem em Costa Rica (1989-1990), Nicarágua e Honduras (1995-1996). As razões para tanto são obscuras. 0 cientista francês J acques Avelino sugere que essas epidemias podem ser explicadas pelo "excesso de confiança e/ou perda de conhecimento da parte dos produtores; menor cuidado pelas fazendas por limitações econômicas; substituição insuficiente dos tipos susceptíveis de café por outros resistentes; falta de pesquisa sobre a ferrugem ou até mesmo mudança climática". ${ }^{37} \mathrm{Um}$ artigo publicado na revista colombiana Semana argumentou que muitos cafeicultores não tinham levado a doença a sério porque seus efeitos iniciais eram freqüentemente amenos. 0 artigo também abordava a relutância dos cafeicultores ao uso de fungicidas feitos a partir do cobre, atribuindo-Ihes falta de compreensão do papel desse remédio no tratamento da doença. Embora o artigo não sugerisse, o custo relativamente alto desses fungicidas também pode ter sido outro fator para sua rejeição. ${ }^{38}$

Outro risco em potencial reside no aparecimento de novos tipos de ferrugem. Somente uma dezena entre as trinta formas da ferrugem são presentes no Hemisfério Ocidental, e ainda é possível que a introdução ou emergência de um tipo mais virulento possa fazer estragos nas plantações. J á existem evidências que a suposta resistência do café híbrido Catimor - largamente plantado na América Latina - está "caindo por terra" nas fazendas do sul da Ásia, ou seja, novas e mais virulentas formas estão emergindo. Isso

35 IADB, USAID, World Bank. Managing the competitive transition of the coffee sector in Central America. (Prepared for the Regional Workshop "The coffee crisis and its impact in Central America: situation and lines of action") Antigua/Guatemala, April 3-6, 2002, p.17-18.

36 Adiós al café. Semana, Bogotá, 30/07/2001.

37 AVELINO. La Roya Anaranjada del Cafeto, p.233.

38 Matrimonio fracasado: la convivencia con la roya se volvió una pesadilla. Semana. Bogotá, 07/07/1990. 
levantou a possibilidade de que os cafés Catimor nas Américas também perderão sua resistência nos próximos anos. ${ }^{39}$

À medida que os velhos modelos de desenvolvimento se fragmentam, novos modelos emergem gradualmente em seu lugar. Em particular, o paradigma da "sustentabilidade" agora predomina na produção de café. Esse conceito possui diferentes significados para diferentes pessoas. Contudo, há alguns pontos comuns. Economicamente, o objetivo da produção de café sustentável é gerar um ganho confiável para os cafeicultores. Ecologicamente, a produção sustentável é feita de forma a preservar o aumentar o "capital natural" - as fontes orgânicas da fazenda. A sustentabilidade substituiu a "tecnificação" como paradigma dominante, tanto na pesquisa agrícola quando no trabalho de desenvolvimento. Essa noção era particularmente aplicável nas regiões cafeicultores da América Latina: o café "tecnificado" parecia ser o arquétipo de um cultivo socialmente e cientificamente insustentável. O Primeiro Congresso de Café Sustentável, realizado no U.S. National Zoo, em 1996, ajudou a aproximar os diversos grupos de cientistas e planejadores, e difundiu a idéia do café sustentável entre as comunidades especializadas. ${ }^{40}$ Proliferaram estudos sobre 0 valor econômico, social e ecológico do café tradicionalmente "sombreado".

A segunda grande transformação no mercado global de café foi o rápido crescimento dos cafés "especiais" - cafés luxuosos de alta qualidade promovidos por companhias tais como Starbucks. Nos últimos vinte anos, esse tem sido o setor mais dinâmico do mercado global de café. Os tipos especiais atraíram consideravelmente a imprensa e os estudiosos, mas ainda respondem por apenas $20 \%$ do mercado global do produto. Um importante setor do mercado de cafés especiais são os "cafés éticos": o fair trade e os cafés orgânicos certificados, ambos projetados para atender os novos padrões internacionais de sustentabilidade ecológica e social. Esses cafés oferecem, aos seus cultivadores, um preço significativamente maior do que os cafés normais. Geralmente, o mercado de cafés especiais somente se interessa por arábicas de alta qualidade, tais como os cultivados no México, América Central, Etiópia, Kênia, e uma dezena de outros locais. Não se incluem os arábicas regulares produzidos no Brasil, nem aqueles cultivados na África e Ásia. ${ }^{41}$

39 RODRIGUES J r, C.J . \& ESKES, A.B. resistance to coffee leaf rust and coffee berry disease. In: Coffee: growing, processing, sustainable production, p.558.

40 Ver: RICE, RobertA.; HARRIS, Ashley M. \& and MCLEAN, J ennifer. (eds.) Proceedings of the First Sustainable Coffee Congress. Washington DC: US National Zoo, 1996.

41 Sobre o "fair trade" e café orgânico certificado, ver MARTINEZ-TORRES, Maria Elena. Organic coffee: sustainable development by Mayan Farmers. Athens: O hio University Press, 2006; J AFFEE, Daniel. Brewing justice: Fair Trade coffee, sustainability, and survival. Berkeley: University of California Press, 2007; FRIDELL, Gavin. Fair Trade coffee: the prospects and pitfalls of market-driven social justice. Toronto: University of Toronto Press, 2007.

NT: Fair Trade é um movimento de organizações internacionais em prol da produção e comércio realizados segundo certas normas éticas de condições de trabalho, respeito ao ambiente, às relações de gênero, transparência e respeito, ver www..en.wikipedia.org, consulta dia 12/03/2008. 
A instável economia global do café associada à ênfase emergente na sustentabilidade e crítica da "tecnificação" transformaram a batalha contra a ferrugem. Estudos de agro-ecologia sugeriram que algumas formas de cultivo podem manter níveis gerenciáveis de ferrugem, assim como de outras doenças. Questionaram-se alguns dos pressupostos fundamentais da "tecnificação", como o de que a presença de sombreamento por árvores intensificaria a infestação pela ferrugem. Estudos conduzidos em Honduras mostram que a relação entre ferrugem e sombras não é tão simples, e depende, na verdade, de uma gama de padrões de manejo. Estudos de fazendas rústicas de pequenos proprietários no México mostram que a incidência da ferrugem era mais baixa em áreas onde havia mais camadas de vegetação geradora de sombras. Naqueles ecossistemas, os níveis médios de ferrugem raramente alcançavam $10 \%$. Por outro lado, a incidência de ferrugem era maior em áreas onde havia mais trilhas (onde havia menos obstáculos físicos à expansão dos esporos, e um número maior de pessoas e animais que poderiam disseminar os esporos). Em alguns lugares, os fazendeiros entusiasticamente abraçaram o cultivo de café "orgânico intensivo", inspirados tanto pelo conhecimento tradicional e por novas pesquisas em agroecologia e agrosilvicultura. ${ }^{42}$ Ainda não é claro se esses estudos liderarão maiores mudanças no cultivo de café nas Américas.

Os novos paradigmas do café transformaram a batalha contra a ferrugem. Os cultivadores continuam a usar fungicidas de cobre como chave no manejo da epidemia. Mas tais fungicidas são caros, e contaminam o solo. Os plantadores de café enfrentam considerável pressão das empresas de torrefação e dos consumidores para reduzir o uso de insumos químicos, ou para eliminá-los completamente. Outra opção seria mudar para os cafés híbridos resistentes à ferrugem. Para os fazendeiros preocupados com qualidade, especialmente aqueles que produzem os cafés especiais, adotar os híbridos pode representar um grande risco econômico. "O tipo de empresário do setor de torrefação, que pode ser encontrado na conferência anual da Associação de Cafés Especiais da América (SCAA)", escreve o cientista britânico Peter Baker, "odeia o Catimor, é rico, influente e implacável". ${ }^{43}$ Seria possível, em teoria, produzir um café resistente à ferrugem usando engenharia genética. Entretanto, os consumidores na América do Norte e, especialmente, na Europa, mostraram considerável resistência aos alimentos geneticamente modificados. Ao mesmo tempo, muitos produtores relutam em adotar os novos híbridos resistentes à ferrugem. Eles desejam

42 Para pesquisas recentes explorando a conexão entre as sombras e a incidência de ferrugem do café, ver: AVELINO; WILOCQUET; SAVARY. Effects of crop management patterns on coffee rust epidemics. Plant Pathology, v.53, p.541-547, 2004; SOTO-PINTO, L.; PERFECTO, I. \& CABALLERO-NIETO, J . Shade over coffee: its effects on berry borer, leaf rust, and spontaneous herbs in Chiapas, Mexico. Agroforestry Systems, v.55, n.1, p.37-45, J une 2002. Sobre agricultura organic intensive, ver: MARTINEZ-TORRES. Organic agriculture.

43 BAKER, Peter S. Keeping the faith: coffee breeding in an age of extremes. In: ZAMBOLIM, L.; ZAMBOLIM, E.M.; VÁRZEA, V.M.P. (eds.) Durable resistance to coffee leaf rust. Viçosa: Universidade Federal de Viçosa, 2005, p.31. 
produzir um café de alta qualidade e alta lucratividade para os mercados, e temem que tais híbridos produzam frutos de gosto e qualidade inferior. A busca por uma forma ecologica e economicamente sustentável de manejo de café ainda prossegue.

\section{Doenças, commodities e História Ambiental}

Os historiadores dedicados ao estudo das commodities devem sempre se confrontar com o risco de que "fetichismo das mercadorias" supervalorize o papel de uma determinada mercadoria nas mudanças históricas. Os historiadores das doenças, igualmente, devem evitar o risco similar de "fetichismo das doenças". Embora a epidemia da ferrugem tenha sido o centro da presente narrativa, ela foi apenas uma entre muitas mudanças que atingiram a indústria americana do café desde a Segunda Guerra Mundial. Em momentos-chave, ela mobilizou cultivadores e instituições públicas. Em outros, perdeu força e tornou-se secundária. Os cultivadores de café, em vários momentos e locais, também se preocuparam com geadas e secas, com outras doenças e pestes (mais seriamente, a broca-do-café), com a instabilidade dos preços, com conflitos civis, e incontáveis outros problemas. Cada um desses fatores oferece aos historiadores diferentes pontos de vista a partir dos quais a história ambiental do café pode ser estudada. 